\title{
Pharmacological Features of the Gall Bladder and Its Vascular Bed of the Dog in sit.
}

\author{
Kiyoshi Tamura, Masao Endoh and Koroku Hashimoto \\ Department of Pharmacology and Experimental Therapeutics, \\ Tohoku University School of Medicine, Sendai
}

\begin{abstract}
Tamura, K., Endoh, M. and Hasmimoto, K. Pharmacological Features of the Gall Bladder and Its Vascular Bed of the Dog in situ. Tohoku J. exp. Med., 1971, 104 (2), 157-169 _ Pharmacological features of the gall bladder and its vascular bed were studied by means of the intra-arterial administration of various substances in the $\operatorname{dog}$ in situ. The contraction of the gall bladder was produced by various compounds as follows: Cholinergic drugs, kinin substances, histamine, ganglion stimulants, ouabain, $\mathrm{BaCl}_{2}$ and $\mathrm{CaCl}_{2}$. Meanwhile, adrenergic drugs, ganglion blocking agents, lys-vasopressin, smooth muscle relaxants, $\mathrm{KCl}$ and $\mathrm{MgCl}_{2}$ relaxed the gall bladder. DMPP, 5-HT, nicotine, lobeline, angiotensin and ATP caused a biphasic response, i.e., a contraction followed by a relaxation or a relaxation followed by a contraction. The pharmacological features of cholecystic arteries are not the same as those of the gall bladder: Cholinergic and adrenergic drugs except isoprenaline, and ganglion stimulating and blocking agents produced opposite effects, while smooth muscle stimulants and relaxants acted similarly on both. Among polypeptides, lys-vasopressin relaxed the gall bladder, cholecystokinin constricted it, and gastrin and oxytocin caused no response, while the former constricted the artery and the latter three dilated it. $\_$gall bladder; cholecystic artery; polypeptide
\end{abstract}

Since Bainbridge and Dale (1905) investigated the nervous control of the canine gall bladder, many reports were published on the responses to various substances, including cholinergic and adrenergic compounds, histamine, cholecystokinin, bile salts and morphine (Lieb and McWhorter, 1915; Halpert and Lewis, 1930, Gaensler et al. 1948). These studies have been done on whole animals by intravenous administration of compounds or on excised preparations kept in the Tyrode solution. The present authors perfused the canine cholecystic artery with the blood conducted from the femoral artery under a constant perfusion pressure, and drugs were given close-arterially. This enabled the authors to investigate the pharmacological features of the gall bladder.

In a previous paper, Hashimoto and Kumakura (1965) investigated vascular responses to various substances of the mesenteric, renal, coronary and femoral arteries and classified drugs into six groups. Soon later Matsumura et al. (1968) studied the pharmacological features of the vasculature of the urinary bladder,

Received for publication, December 11, 1970. 
and Yamamoto et al. (1970) studied those of the skin. For extension of such comparative studies, the vascular response of the gall bladder was also investigated in this paper.

\section{MeThoDs}

Twenty-one mongrel dogs of either sex weighing 8 to $15 \mathrm{~kg}$ were used. The animals were anesthetized initially by an intravenous injection of $30 \mathrm{mg} / \mathrm{kg}$ of sodium pentobarbital, and anesthesia was maintained by infusion of pentobarbital at a rate $4.5 \mathrm{mg} / \mathrm{kg} /$ $\mathrm{hr}$ into the jugular vein. The gall bladder was exposed by a wide incision of the abdominal wall along the costal margin in both sides. The cholecystic artery was isolated carefully from the surrounding tissue. A polyethylene cannula, about $1 \mathrm{~mm}$ in o.d., was inserted into the distal end of the cut cholecystic artery, through which arterial blood from the femoral artery was perfused. The initial level of blood pressure, 100 to $150 \mathrm{~mm} \mathrm{Hg}$, was maintained by transfusion of the fresh blood obtained from other dogs. Sodium w-heparin (Hashimoto et al., 1963), 500 units per $\mathrm{kg}$ was given just prior to the cannulation of the cholecystic artery and additional dose of 1000 units at one-hour intervals. The phrenic nerves were cut bilaterally and costal margin of the diaphragm was removed in order to minimize the effect of the respiratory movements. The trachea was cannulated and a positive pressure respiration was performed by a Harvard respirator (Model 607) at 15 to $20 \mathrm{cpm}$ with a tidal volume of $20 \mathrm{ml}$ per $\mathrm{kg}$ of body weight. An electromagnetic flowmeter (Nihon Kohden MF-2a) was used for measuring the blood flow in the cholecystic artery. A polyethylene tube, $3 \mathrm{~mm}$ in o.d., was inserted through the common bile duct into the gall bladder and connected with a strain gauge pressure-probe (Toyo Sokki, LPU 0.1) for the measurement of intravesical pressure, which indicates the movement of the gall bladder. The blood flow in the cholecystic artery, the intravesical pressure and the systemic blood pressure at the carotid artery were recorded on an ink-writing oscillograph (Nihon Kohden, WI-205R). The exposed part was covered with a transparent plastic film to keep it moist and warmed with an infra-red lamp between $37^{\circ}$ and $39^{\circ} \mathrm{C}$. Fig. 1 shows a schematic diagram of the experimental set-up.

Drugs used and their dose ranges are listed in Table 1. Doses of nicotine, $l$-noradrenaline, $l$-adrenaline, lys-vasopressin, gastrin, gastrin-like tetrapeptide (NK-T), oxytocin, eledoisin, adenosine, uridine, DPN and TPN are expressed in terms of the bases. All other drugs were referred to their corresponding salts. One microgram of oxytocin corresponds to 0.46 international units (Boissonas et al., 1961) of oxytocin activity and one microgram of lys-

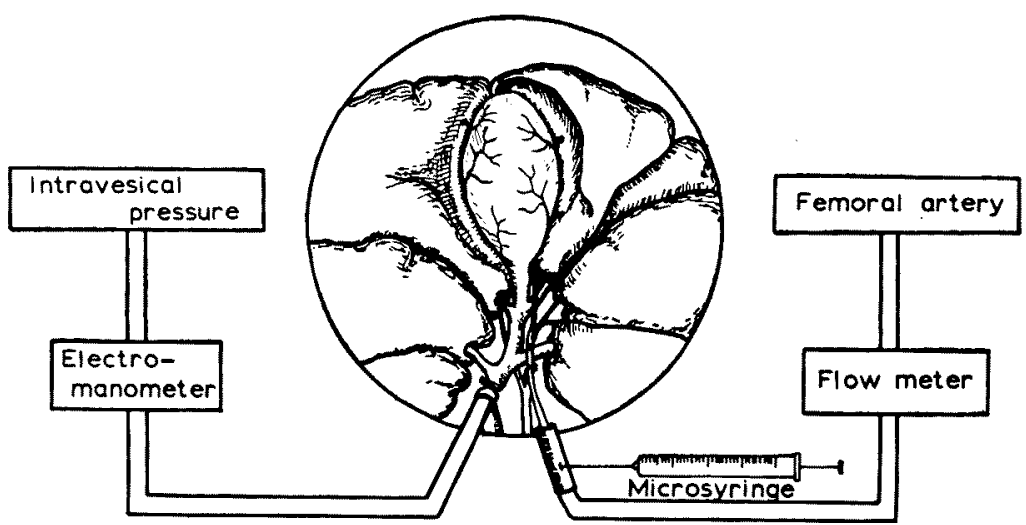

Fig. 1. Diagram for perfusion of the cholecystic artery, and measurements of cholecystic blood flow and of intravesical pressure of the gall bladder. 
TABLE 1. Dose ranges of investigated drugs

\begin{tabular}{|c|c|c|c|}
\hline Compounds & $\begin{array}{l}\text { No. of } \\
\text { exp. }\end{array}$ & $\mu \mathrm{g}$ & $\begin{array}{l}\text { Drug concentration } \\
\text { in blood }(\mathrm{g} / \mathrm{ml})_{+}^{+}\end{array}$ \\
\hline \multicolumn{4}{|l|}{ Parasympathomimetics } \\
\hline Acetylcholine chloride & 21 & $0.01-10$ & $3 \times 10^{-8}$ to $10^{-5}$ \\
\hline Methacholine chloride & 3 & $0.1-10$ & \\
\hline Carbachol chloride & 3 & $0.1-10$ & $3 \times 10^{-7}$ to $10^{-5}$ \\
\hline Bethanechol chloride & 3 & $0.1-30$ & \\
\hline Choline chloride & 3 & $1-100$ & $3 \times 10^{-6}$ to $10^{-4}$ \\
\hline Pilocarpine hydrochloride & 2 & $1-10$ & $3 \times 10^{-6}$ to $10^{-5}$ \\
\hline \multicolumn{4}{|l|}{ Sympathomimetics } \\
\hline l-Noradrenaline (base) & 12 & $0.01-1$ & $3 \times 10^{-8}$ to $10^{-6}$ \\
\hline$l$-Adrenaline (base) & 12 & $0.01-1$ & $3 \times 10$ to 10 \\
\hline$l$-Isoprenaline hydrochloride & 7 & $0.01-0.1$ & $3 \times 10^{-8}$ to $10^{-7}$ \\
\hline Dopamine hydrochloride & 6 & $10-30$ & 3 to $9 \times 10^{-5}$ \\
\hline Tyramine hydrochloride & 6 & $1-100$ & $3 \times 10^{-6}$ to $10^{-4}$ \\
\hline Phenylephrine hydrochloride & 6 & $0.1-10$ & $3 \times 10^{-7}$ to $10^{-5}$ \\
\hline Methoxamine hydrochloride & 2 & $1-10$ & $3 \times 10^{-6}$ to $10^{-5}$ \\
\hline Ephedrine hydrochloride & 3 & $0.1-10$ & $3 \times 10^{-7}$ to $10^{-5}$ \\
\hline \multicolumn{4}{|l|}{ Active polypeptides } \\
\hline Bradykinin (synthetic) & 6 & $0.01-0.1$ & $3 \times 10^{-8}$ to $10^{-7}$ \\
\hline Eledoisin (synthetic) & 4 & $0.01-0.1$ & $3 \times 10 \quad 6010$ \\
\hline Kallikrein & 3 & $0.01-0.1^{*}$ & \\
\hline Angiotensin (synthetic) & 6 & $0.01^{-1}$ & \\
\hline Lys-vasopressin (synthetic) & 4 & $0.01-1$ & $3 \times 10^{-8}$ to $10^{-6}$ \\
\hline Oxytocin (synthetic) & 4 & $0.01-1$ & \\
\hline Cholecystokinin & 6 & $0.01-0.1^{*}$ & \\
\hline Gastrin & 2 & $0.1-2^{*}$ & \\
\hline \multirow{2}{*}{\multicolumn{4}{|c|}{$\begin{array}{l}\text { Gastrin-like tetrapeptide } \\
\text { Ganglion stimulating agents }\end{array}$}} \\
\hline & & & \\
\hline Nicotine & 6 & $1-10$ & $3 \times 10^{-6}$ to $10^{-5}$ \\
\hline Tetramethylammonium chloride & 3 & $10-30$ & 3 to $9 \times 10^{-5}$ \\
\hline 1,1-Dimethyl-4-phenylpiperazinium iodide (DMPP) & 11 & $1-10$ & $3 \times 10^{-6}$ to $10^{-5}$ \\
\hline Lobeline hydrochloride & 2 & $10-30$ & 3 to $9 \times 10^{-5}$ \\
\hline 4-(m-chlorophenylcarbamoyloxy)-2-butynyltri- & 2 & $10-30$ & 3 to $9 \times 10^{-6}$ \\
\hline $\begin{array}{l}\text { methylammonium chloride (McN-A-343) } \\
\text { Ganglion blocking agent }\end{array}$ & & & \\
\hline $\begin{array}{l}\text { Ganglion blocking agent } \\
\text { Tetraethylammonium bromide }\end{array}$ & 2 & $1^{\dagger}$ & $3 \times 10^{-3}$ \\
\hline \multirow{2}{*}{\multicolumn{4}{|c|}{$\begin{array}{l}\text { Tetraethylammonium bromide } \\
\text { Other biogenic amines }\end{array}$}} \\
\hline 5-Hydroxytryptamine creatinine sulfate & 6 & $0.1-10$ & \\
\hline Histamine dihydrochloride & 6 & $0.1-10$ & $3 \times 10^{-7}$ to $10^{-5}$ \\
\hline \multirow{2}{*}{\multicolumn{4}{|c|}{$\begin{array}{l}\text { Histamine dihydrochloride } \\
\text { Nucleosides and nucleotides }\end{array}$}} \\
\hline Adenosine hydrate & 6 & $10-30$ & \\
\hline AMP (disodium salt hydrate) & 3 & $10-30$ & \\
\hline ADP (trisodium salt) & 3 & $10-30$ & \\
\hline ATP (disodium salt) & 5 & $10-30$ & \\
\hline Uridine (base) & 3 & $10-30$ & 3 to $9 \times 10^{-5}$ \\
\hline UMP (disodium salt dihydrate) & 3 & $\begin{array}{l}10-30 \\
10-30\end{array}$ & \\
\hline UDP (sodium salt trihydrate) & 3 & $\begin{array}{l}10-30 \\
10-30\end{array}$ & \\
\hline UTP (trisodium salt dihydrate) & 3 & $\begin{array}{l}10-30 \\
10-30\end{array}$ & \\
\hline DPN (base) & 2 & $\begin{array}{l}10-30 \\
10\end{array}$ & \\
\hline $\begin{array}{l}\text { DPN (base) } \\
\text { TPN (base) }\end{array}$ & 2 & $\begin{array}{l}10 \\
10\end{array}$ & $3 \times 10^{-5}$ \\
\hline \multirow{2}{*}{\multicolumn{4}{|c|}{$\begin{array}{l}\text { TPN (base) } \\
\text { Miscellaneous compounds }\end{array}$}} \\
\hline Papaverine hydrochloride & 3 & & \\
\hline Theophylline ethylendiamine & 3 & $10-30$ & 3 to $9 \times 10^{-5}$ \\
\hline Ouabain (crystal) & 2 & $1-10$ & $3 \times 10^{-6}$ to $10^{-5}$ \\
\hline Procaine hydrochloride & 2 & $1 \dagger^{1}$ & \\
\hline $\mathrm{KCl}$ & 2 & $1^{\dagger}$ & \\
\hline $\mathrm{MgCl}_{2}$ & 2 & $1 \dagger$ & $3 \times 10^{-3}$ \\
\hline $\mathrm{CaCl}_{2}$ & 2 & $1^{\dagger}$ & \\
\hline $\mathrm{BaCl}_{2}$ & 2 & $1 \dagger$ & \\
\hline \pm The value was calcule & from & ean blood & flow. \\
\hline
\end{tabular}




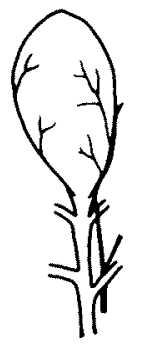

$\frac{10}{21}$

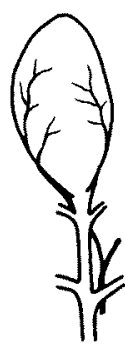

$\frac{9}{21}$

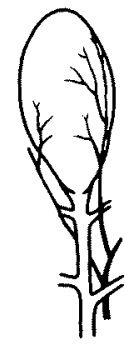

$\frac{2}{21}$

Fig. 2. Anatomical differences in blood supply to the gall bladder.

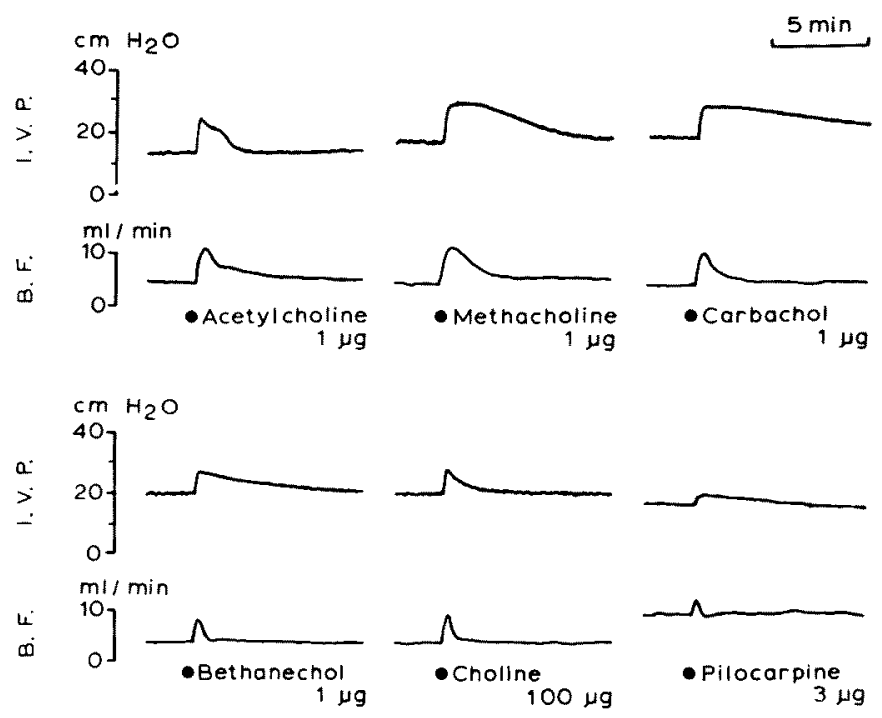

Fig. 3 Responses to parasympathomimetics. The intravesical pressure (I.V.P.) of the gall bladder in $\mathrm{cm} \mathrm{H}_{2} \mathrm{O}$ and the blood flow (B.F.) of the cholecystic artery in $\mathrm{ml} / \mathrm{min}$.

vasopressin to 0.27 international units (Fraschini et $a l ., 1964$ ) of pressor activity. $l$-Noradrenaline and $l$-adrenaline dissolved at a concentration of $10 \mathrm{mg} / \mathrm{ml}$ in $0.01 \mathrm{~N}$-HCl were diluted with $0.9 \%$ saline to make desired concentrations. All other drugs were dissolved in $0.9 \%$ saline. The volume of drug solution was 0.01 and $0.03 \mathrm{ml}$ which was administered intra-arterially by Jintan microinjectors in a period of 4 and $10 \mathrm{sec}$, respectively.

\section{Results}

\section{A) Anatomical considerations on the canine gall bladder}

The initial intravesical pressure measured between $5 \mathrm{~min}$ and $20 \mathrm{~min}$ after cannulation of the common bile duct was $12.5 \pm 1.2 \mathrm{~cm} \mathrm{H} \mathrm{H}_{2} \mathrm{O}$ (mean \pm s.E., $\mathrm{n}=17$ ). Mean and s.e. of the blood flow of the cholecystic artery was $5.1 \pm 0.7 \mathrm{ml} / \mathrm{min}$ at $120 \pm 12.5 \mathrm{~mm} \mathrm{Hg}(\mathrm{n}=13)$ of the mean systemic blood pressure. The cholecystic artery ran along the right side of the common bile duct in 9 dogs, along the left side in 10 dogs and both sides in 2 cases as shown in Fig. 2. 


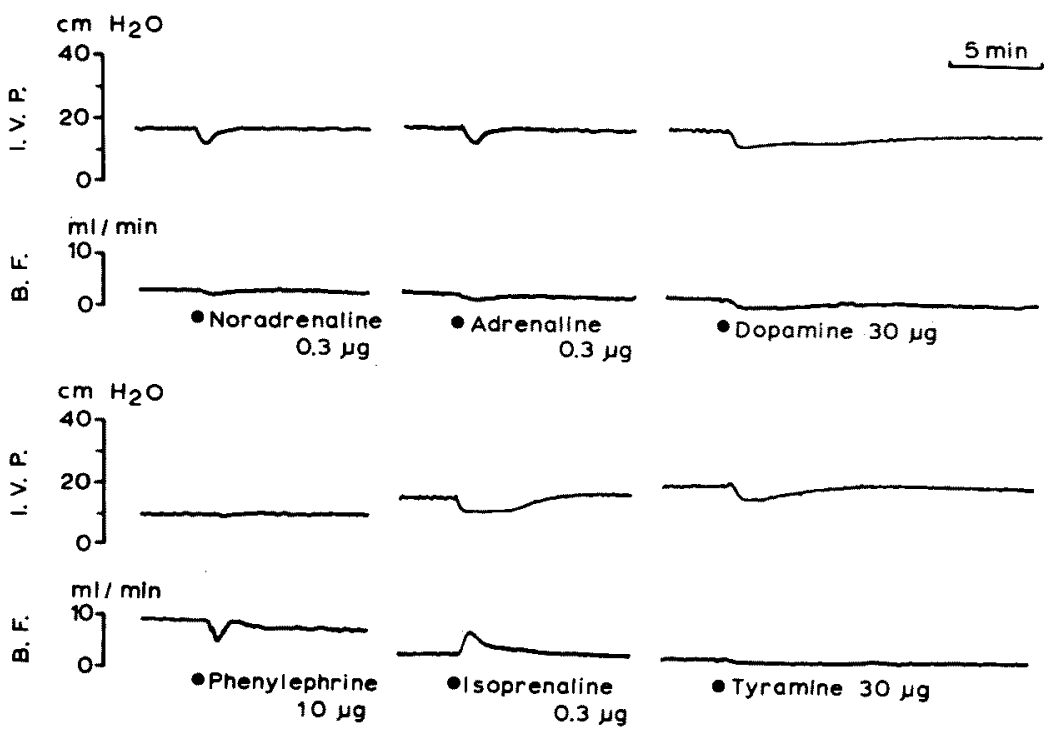

Fig. 4. Responses to sympathomimetics. Scales are the same as those in Fig. 3.

B) Responses of the gall bladder and its vascular bed to various substances

1) Cholinergic compounds (Fig. 3). Fig. 3 shows one of the typical experiments.

a) Effect on the contractility of the gall bladder. Acetylcholine, bethanechol, carbachol, methacholine, choline and pilocarpine produced an increase in the intravesical pressure as shown in upper curves of Fig. 3. Acetylcholine caused a rapid contraction but its duration was short. Effects on the contractility of methacholine, carbachol and bethanechol were long-lasting. Choline acted in a similar manner but a larger dose from 500 to 1,000 times was required in order to obtain similar response. Pilocarpine caused a similar but weaker response than did choline esters.

b) Effect on the vascular bed. All of the cholinergic substances mentioned above caused a marked vasodilation. These vascular effects were shorter in duration than their effects on the motility.

2) Adrenergic compounds (Fig. 4). Fig. 4 shows one of the typical experiments.

a) Effect on the contractility of the gall bladder.

Noradrenaline, adrenaline, isoprenaline, dopamine and tyramine induced a relaxation. A slight contraction was observed following a marked relaxation by use of noradrenaline and adrenaline in a few cases (2 out of 12). Phenylephrine had almost no effect on the gall bladder even when the vasoconstriction occurred obviously. Dopamine and tyramine produced a long-lasting relaxation and their potencies were $1 / 30$ to $1 / 100$ of that of noradrenaline.

b) Effect on the vascular bed. All the seven sympathomimetic compounds except isoprenaline produced a vasoconstriction. Isoprenaline elicited a vasodila- 

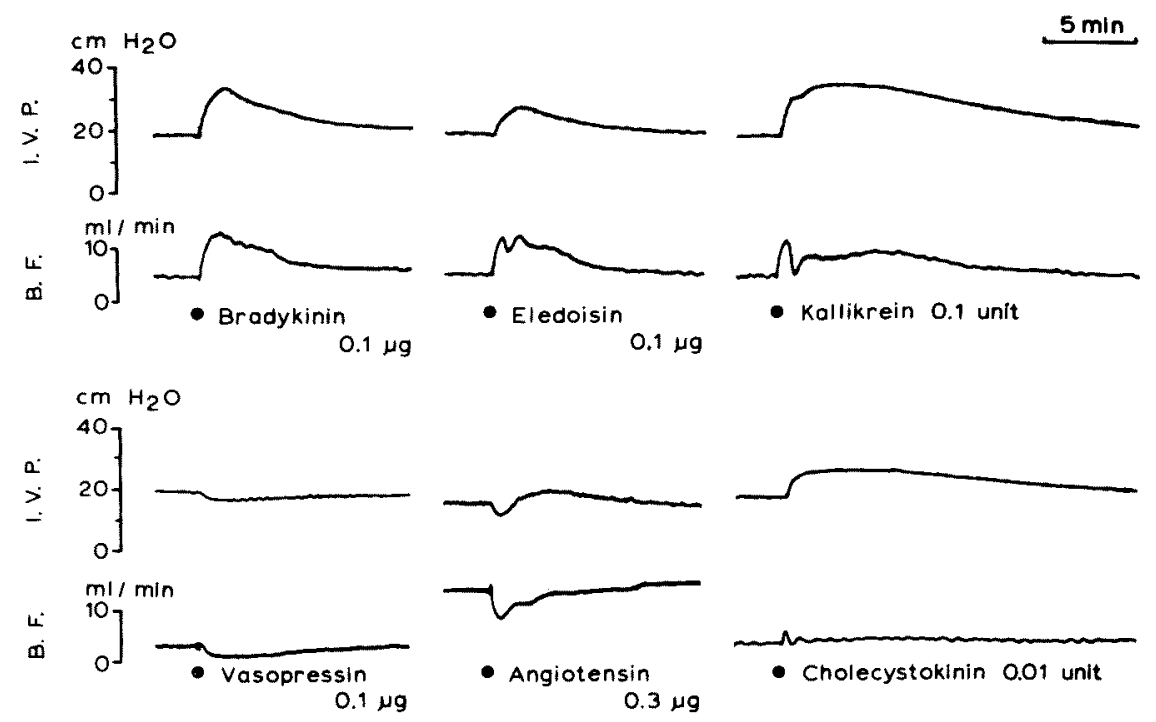

Fig. 5. Responses to active polypeptides. Scales are the same as those in Fig. 3.

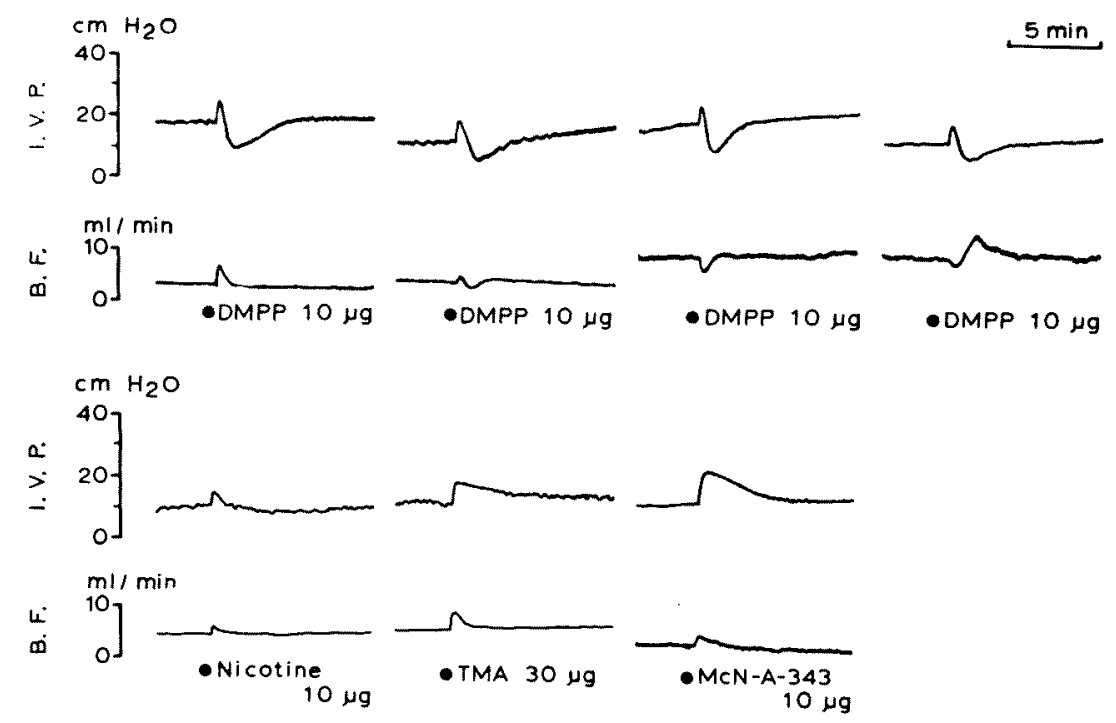

Fig. 6. Responses to ganglion stimulating agents. Scales are the same as those in Fig. 3.

tion. The potencies of dopamine and tyramine were $1 / 30$ to $1 / 100$ of those of adrenaline and noradrenaline but the former two compounds were long-acting.

3) Active polypeptides (Fig. 5).

a) Effect on the contractility of the gall bladder. Bradykinin, eledoisin and kallikrein caused an increment of intravesical pressure. Bradykinin and eledoisin were about 50 times more potent than choline esters on the molar base. Angiotens- 


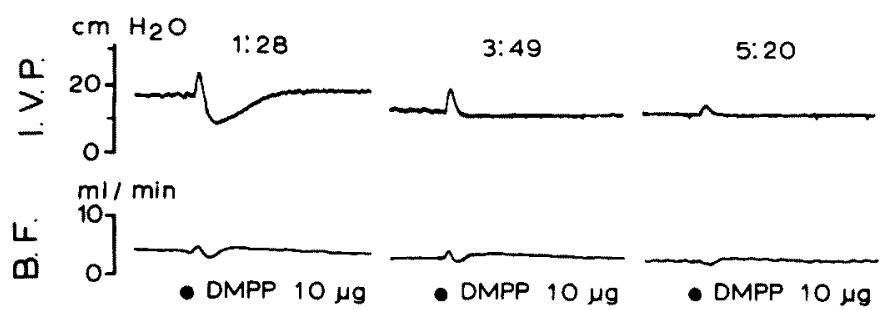

Fig. 7. Changes in responses to successive administrations of DMPP. Scales are the same as those in Fig. 3.

in caused an initial relaxation followed by a contraction. Lys-vasopressin produced a simple and long-lasting relaxation in 3 out of 4 cases and no effect in the other. Gastrin and gastrin-like tetrapeptide (NK-T), and oxytocin in $0.1 \mu \mathrm{g}$ produced no response. Cholecystokinin caused a powerful contraction of the canine gall bladder in 5 out of 6 cases, and was about 10 times more potent than bradykinin. Chlorobutanol used as preservant of lys-vasopressin had no effect on the gall bladder at the concentration used for administration of the drug.

b) Effect on the vascular bed. Bradykinin, eledoisin, kallikrein, gastrin and gastrin-like tetrapeptide, and oxytocin produced a vasodilation. Lys-vasopressin and angiotensin constricted the artery, while cholecystokinin dilated it slightly in 4 out of 6 cases and caused no response in the others.

4) Ganglion stimulating agents (Figs. 6 and 7).

a) Effect on the contractility of the gall bladder. Nicotine, TMA, McN-A-343 and lobeline contracted the gall bladder. DMPP produced a biphasic response, $i$. e., a contraction followed by a relaxation in 8 out of 11 cases and a simple contraction in 3 cases. A biphasic response elicited by DMPP was modified by repetitive applications of $10 \mu \mathrm{g}$ as shown in Fig. 7. The relaxation gradually diminished and ultimately disappeared. The initial contraction was rather persistent but finally diminished to a small response.

b) Effect on the vascular bed. Ganglion stimulating agents, nicotine, TMA, McN-A-343 and lobeline except DMPP produced a vasodilation. Though the experimental condition was almost the same, DMPP caused variable responses in different animals; a vasodilation, a vasoconstriction, a vasodilation followed by a vasoconstriction, and a vasoconstriction followed by a vasodilation. These vascular responses to DMPP diminished by repetitive applications as shown in Fig. 7.

5) Other biogenic amines (Fig. 8).

a) Effect on the contractility of the gall bladder. 5-HT caused an initial contraction followed by a relaxation as did DMPP. Histamine produced a contraction. 

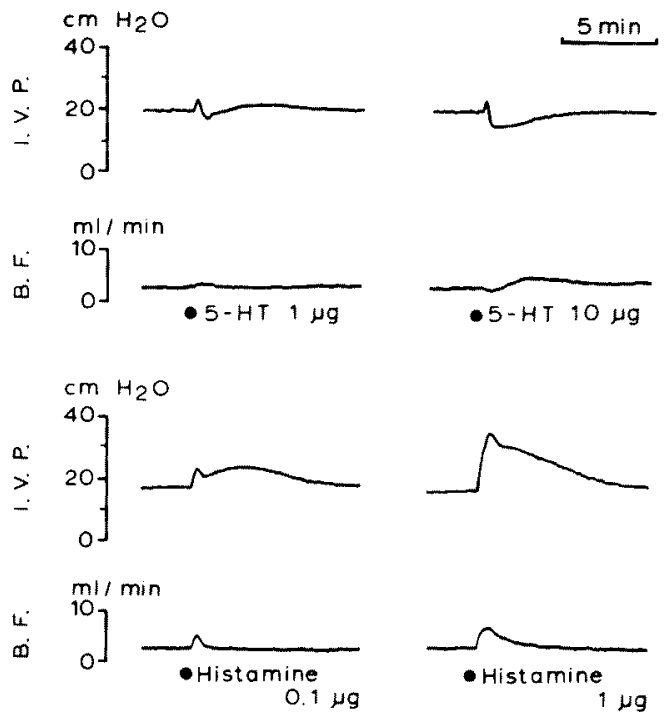

Fig. 8. Responses to other biogenic amines. Scales are the same as those in Fig. 3 .
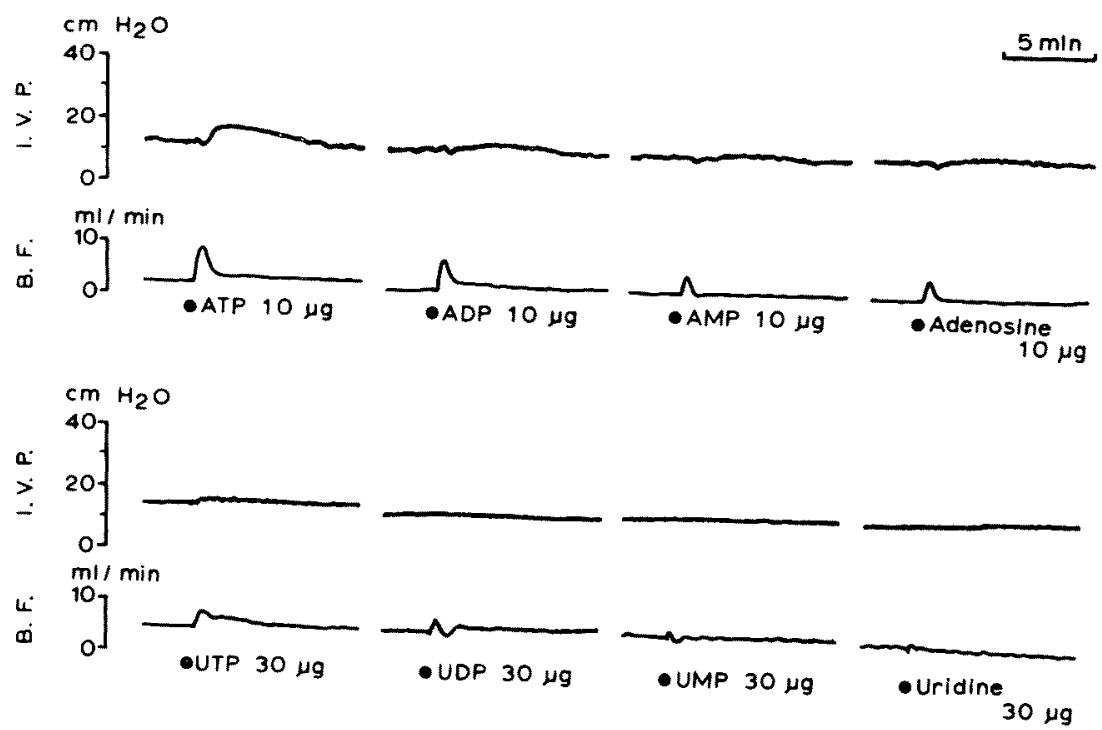

Fig. 9. Responses to the adenine and uridine derivatives. Scales are the same as those in Fig. 3.

b) Effect on the vascular bed. 5-HT caused a slight vasodilation but in large doses this vasodilation was preceded by a slight vasoconstriction. Histamine produced a vasodilation.

6) Nucleosides and nucleotides (Fig. 9).

a) Effect on the contractility of the gall bladder. ATP caused a relaxation followed by a contraction, while ADP, AMP and adenosine up to $30 \mu \mathrm{g}$ did not 

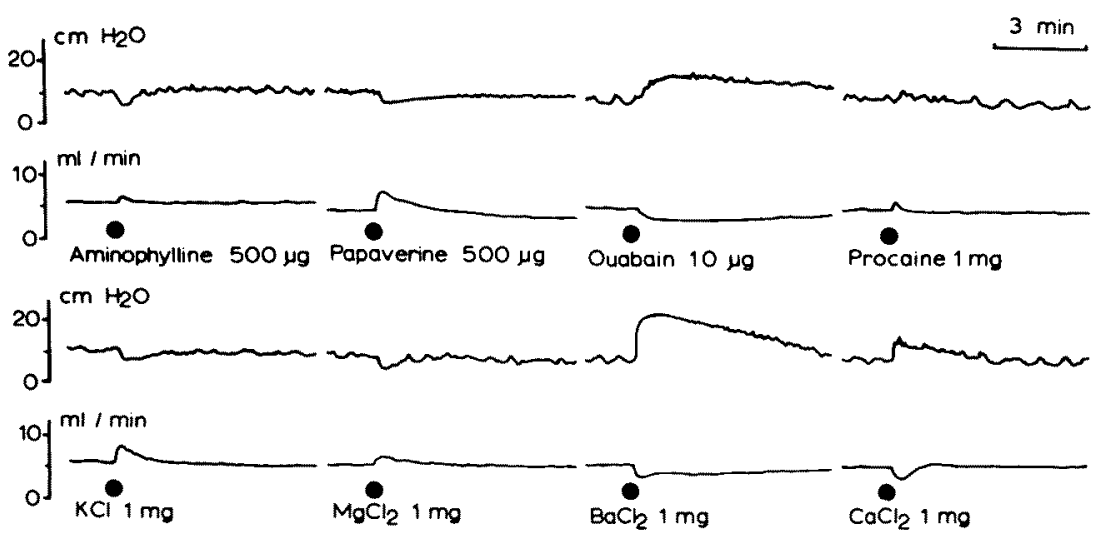

Fig. 10. Responses to miscellaneous agents. Scales are the same as those in Fig. 3 .

cause any significant response. UTP produced a contraction but UDP, UMP and uridine did not produce any response. TPN and DPN caused no response.

b) Effect on the vascular bed. ATP, ADP, AMP, adenosine, TPN and DPN produced a vasodilation. ATP was the most potent and adenosine the weakest. UTP and UDP caused a vasodilation. Other uridine nucleotides had little effect.

7) Miscellaneous agents (Fig. 10).

a) Effect on the contractility of the bladder. Aminophylline and papaverin caused a relaxation. Ouabain elicited a contraction. $\mathrm{CaCl}_{2}$ and $\mathrm{BaCl}_{2}$ produced a contraction, and $\mathrm{KCl}$ and $\mathrm{MgCl}_{2}$ caused a relaxation. Procaine caused no response.

b) Effect on the vascular bed. Aminophylline, papaverine and procaine caused a vasodilation, while ouabain did a vasoconstriction. $\mathrm{CaCl}_{2}$ and $\mathrm{BaCl}_{2}$ caused a vasoconstriction, while $\mathrm{KCl}$ and $\mathrm{MgCl}_{2}$ produced a vasodilation.

C) Classification of investigated drugs on the basis of their effects on the contractility of the gall bladder in reference to its vascular bed

The authors classify the tested drugs to five groups according to their effects on the gall bladder smooth muscle. And drugs of each group are further subdivided into two classes in reference to their vascular effects as shown in Table 2.

Among substances belonging to the first group which produce the contraction of the gall bladder, ouabain, $\mathrm{BaCl}_{2}$ and $\mathrm{CaCl}_{2}$ constrict the vascular bed, while choline, ACh, methacholine, bethanechol, carbachol, pilocarpine, bradykinin, eledoisin, kallikrein, cholecystokinin, TMA, McN-A-343, histamine and UTP dilate it. Drugs belonging to the second group produce the relaxation of the gall bladder. Among them, dopamine, noradrenaline, adrenaline, ephedrine, tyramine, lysvasopressin and TEA produce a vasoconstriction, while isoprenaline, aminophylline, papaverine, $\mathrm{KCl}$ and $\mathrm{MgCl}_{2}$ cause a vasodilation. DMPP, nicotine, lobeline and 5-HT which belong to the third group produce a contraction followed by a relaxation of the gall bladder while they cause a vasodilation. Drugs of the fourth 
TABLE 2. Classification of investigated drugs on the basis of their effects on the gall bladder smooth muscle in reference to its vascular bed

\begin{tabular}{|c|c|c|}
\hline $\begin{array}{l}\text { Effects on contractility } \\
\text { of the gall bladder }\end{array}$ & $\begin{array}{l}\text { Vascular } \\
\text { responses }\end{array}$ & Drugs \\
\hline \multirow[b]{2}{*}{ Contraction } & Constriction & $\mathrm{BaCl}_{2}, \mathrm{CaCl}_{2}$, ouabain \\
\hline & Dilation & $\begin{array}{l}\text { Choline, acetylcholine, methacholine, carbachol, } \\
\text { bethanechol, pilocarpine, bradykinin, eledoisin, } \\
\text { cholecystokinin, TMA, McN-A-343, nicotine, } \\
\text { lobaline, histamine, UTP }\end{array}$ \\
\hline \multirow{2}{*}{ Relaxation } & Constriction & $\begin{array}{l}\text { Dopamine, noradrenaline, adrenaline, ephedrine, } \\
\text { tyramine, lys-vasopressin, TEA }\end{array}$ \\
\hline & Dilation & $\begin{array}{l}\text { Isoprenaline, aminophylline, papaverine, } \mathrm{KCl} \text {, } \\
\mathrm{MgCl}_{2}\end{array}$ \\
\hline \multirow{2}{*}{$\begin{array}{l}\text { Contraction followed } \\
\text { by relaxation }\end{array}$} & Constriction & \\
\hline & Dilation & DMPP, 5-HT \\
\hline \multirow{2}{*}{$\begin{array}{l}\text { Relaxation followed } \\
\text { by contraction }\end{array}$} & Constriction & Angiotensin \\
\hline & Dilation & ATP \\
\hline \multirow[b]{2}{*}{ No effect } & Constriction & Phenylephrine, methoxamine \\
\hline & Dilation & $\begin{array}{l}\text { Gastrin, gastrin-like tetrapeptid, oxytocin, ADP, } \\
\text { AMP, adenosine, DPN, TPN, UDP, UMP, } \\
\text { uridine, procaine }\end{array}$ \\
\hline
\end{tabular}

group which cause a relaxation followed by a contraction of the gall bladder are angiotensin and ATP. The former produces a vasoconstriction while the latter dilates the vascular bed. Drugs of the fifth group cause only a vascular response without any effect on the contractility of the gall bladder; a vasoconstriction by phenylephrine and methoxamine and a vasodilation by oxytocin, ADP, AMP, adenosine, TPN, DPN, UDP, UMP and uridine.

\section{Discussion}

The gall bladder responds to cholinergic stimulation with contraction, while to adrenergic one with relaxation. Bainbridge and Dale (1905) have reported that the gall bladder responded both to stimulation of the splanchnic nerve and to intravenous administration of adrenaline with either contraction or relaxation. Later investigation showed that a relaxation was elicited with adrenaline in the canine gall bladder in vivo (Lieb and McWhorter, 1915) and in vitro (Halpert and Lewis, 1930). In the present experiments, dopamine, noradrenaline, adrenaline and isoprenaline caused a relaxation in the majority of cases but phenylephrine and methoxamine known to act mainly on alpha-adrenergic receptors neither contracted nor relaxed the canine gall bladder even with a higher dose up to $10 \mu \mathrm{g}$. Therefore, we conclude that alpha-adrenergic receptors are poorly developed in the canine gall bladder. 
Gall Bladder and Vascular Bed

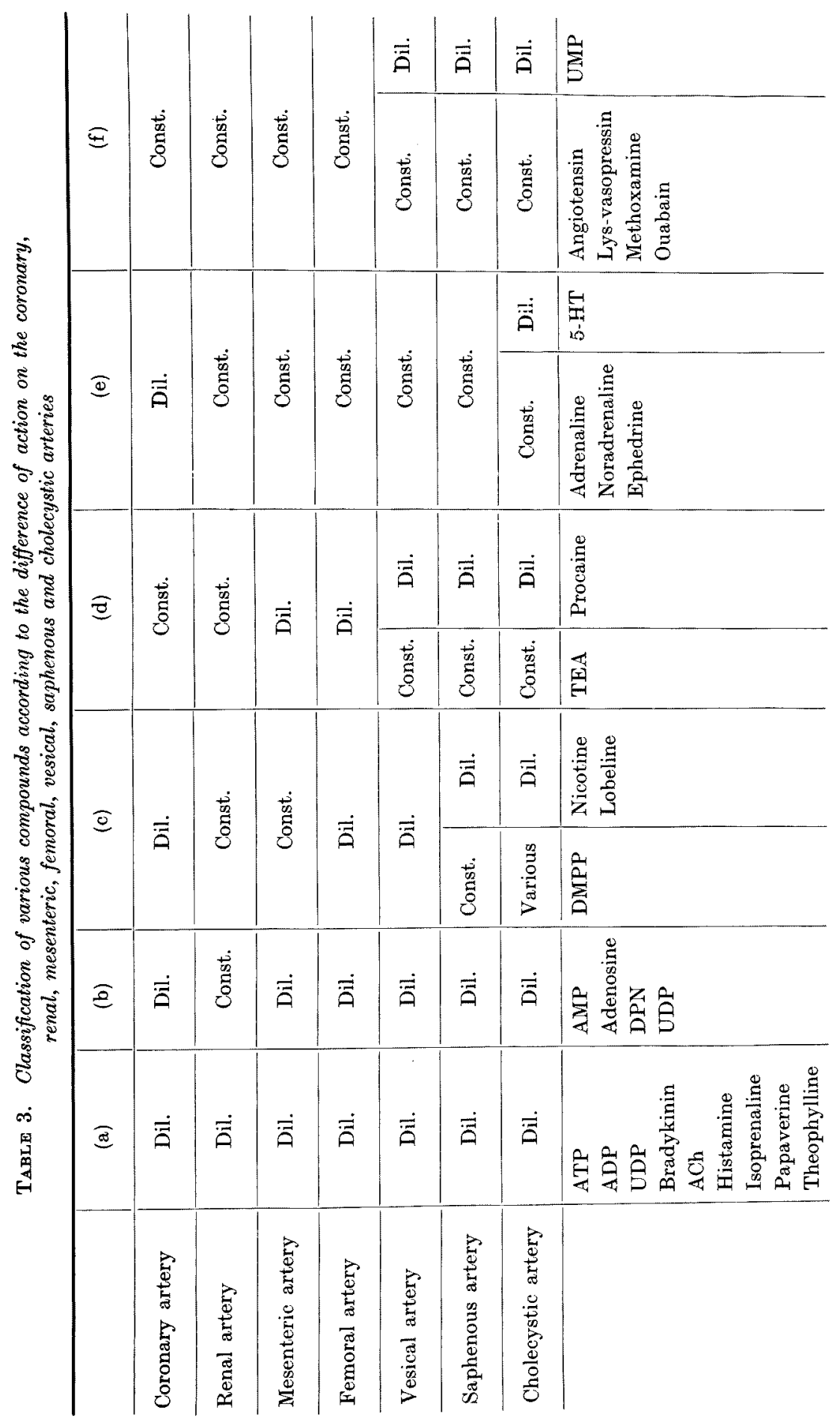


Ivy and Oldberg (1928) first found that the gall bladder responded with a significant contraction to a gastrointestinal hormone which they named as cholecystokinin. Halpert and Lewis (1930), however, reported negative results for cholecystokinin in experiments with the isolated gall bladder of the dog. Jung and Greengard (1933) carried out the experiments with the isolated gall bladder of the guinea pig and found that the total amount of cholecystokinin needed to produce a contraction was about 50 times larger than the intravenous dose. In the present experiments, the gall bladder sensitively responded with a vigorous contraction to intra-arterial cholecystokinin. Thus, cholecystokinin may probably be secured to have a good access to the smooth muscle from the vascular bed as they suggested.

Lys-vasopressin is known to produce a contraction of the gastrointestinal tract and of its vascular bed. In the present experiments, intra-arterial administration of lys-vasopressin caused a relaxation of the gall bladder, while it constricted the cholecystic artery. The relaxation caused by lys-vasopressin will be characteristic of the smooth muscle of the gall bladder.

DMPP caused a biphasic response, a contraction followed by a relaxation, while it dilated the cholecystic artery. DMPP has a ganglion stimulating action on nicotinic sites in parasympathetic ganglia, while sympathetic nerve endings were also stimulated. The DMPP-induced biphasic response may be ascribed to two actions described above. The response to DMPP was diminished by repeated administrations. Especially, the relaxation was more susceptible than the contraction. Birmingham and Wilson (1965) have reported that DMPP may exert an adrenergic blocking effect on the isolated small intestine by a guanethidinelike action. This may be a probable cause for the disappearance of the relaxation.

Matsumura et al. (1968) showed the pharmacological bahaviors of the urinary bladder in the dog by means of the intra-arterial administration of various compounds under constant flow perfusion. In comparison with the results of the urinary bladder there were several differences: 1) DMPP and 5-HT caused contraction of the urinary bladder while a biphasic response, a contraction followed by a relaxation, was observed in the gall bladder. 2) ATP and angiotensin produced a contraction of the former, while biphasic response, relaxation followed by contraction, occurred in the latter. 3) Papaverine and aminophylline elicited no response of the former but relaxation of the latter. 4) Lys-vasopressin, TEA and $\mathrm{KCl}$ produced contraction of the former but relaxation of the latter. 5) Phenylephrine induced contraction of the former but not any response of the latter.

Recently Yamamoto et al. (1970) investigated the responses of the saphenous vascular bed of the dog to various drugs, and supplemented the classification described by Hashimoto and Kumakura (1965). Table 3 shows the present results. According to this classification, all drugs of group (a) also caused a dilation in the cholecystic artery. The drugs of group (b) produced a dilation in the cholecystic artery. In drugs of group (c), nicotine and lobeline caused only a dilation while the effect of DMPP was variable. In drugs of group (d), TEA caused a constric- 
tion of the cholecystic artery likewise of the saphenous, vesical, coronary and renal arteries. Procaine produced a dilation but it constricted the coronary and renal arteries. In drugs of group (e), adrenaline and noradrenaline caused a constriction of the six vascular beds except coronary artery in Table 3. 5-HT caused a constriction of the renal, mesenteric, femoral, vesical and saphenous arteries but a dilation of the coronary and cholecystic arteries.

\section{Acknowledgment}

This study was supported by grants of Pharmacological Research Foundation, Inc., and Nippon Kayaku. We express our thanks to Mrs. Michiko Shirato for type-writing this manuscript.

\section{References}

1) Bainbridge, F.A. \& Dale, H.H. The contractile mechanism of the gall-bladder and its extrinsic nervous control. J. Physiol., 1905, 33, 138-155.

2) Birmingham, A.T. \& Wilson, A.B. An analysis of the blocking action of dimethylphenylpiperazinium iodide on the inhibition of isolated small intestine produced by stimulation of the sympathetic nerves. Brit. J. Pharmacol., 1965, 24, 375-386.

3) Boissonas, R.A., Guttmann, S., Berde, B. \& Konzett, H. Relationships between the chemical structures and the biological properties of the posterior pituitary hormones and their synthetic analogues. Experientia (Basel), 1961, 17, 377-390.

4) Fraschini, F., Mangili, G., Martini, L. \& Motta, M. Neurohypophysial principles and anterior pituitary function. Oxytocin, Vasopressin and their Structural Analogues, edited by J. Rudinger, Proc. 2nd Intern. Pharmacol. Meeting, Pergamon Press, Oxford, 1964, p. 75 .

5) Gaensler, E.A., McGowan, J.M. Henderson, F.F. A comparative study of the action of demerol and opium alkaloids in relation to biliary spasm. Surgery, 1948, 23, 211-220.

6) Halpert, B. \& Lewis, J.H. Experiments on the isolated whole gall bladder of the dog. Amer. J. Physiol., 1930, 93, 506-520.

7) Hashimoto, K. \& Kumakura, S. The pharmacological features of the coronary, renal, mesenteric and femoral arteries. Jap. J. Physiol., 1965, 15, 540-551.

8) Hashimoto, K., Matsuno, M., Yosizawa, Z. \& Shibata, T. A dextrorotatory polysaccharide of very high anticoagulant activity newly isolated from the whale's lung and intestine. Tohoku J. exp. Med., 1963, 81, 93-95.

9) Ivy, A.C. \& Oldberg, E. A hormone mechanism for gall-bladder contraction and evacuation. Amer. J. Physiol., 1928, 86, 599-613.

10) Jung, F.T. \& Greengard, H. Response of the isolated gall bladder to cholecystokinin. Amer. J. Physiol., 1933, 103, 275-278.

11) Lieb, C.C. \& McWhorter, J.E. Action of drugs on the isolated gall-bladder. $J$. Pharmacol. exp. Ther., 1915, 7, 83-98.

12) Matsumura, S., Taira, N. \& Hashimoto, K. The pharmacological behavior of the urinary bladder and its vasculature of the dog. Tohoku J. exp. Med., 1968, 96, 247-258.

13) Yamamoto, M., Sasaki, H., Taira, N. \& Hashimoto, K. Responses of the canine saphenous vascular bed to various biogenic and foreign substances. Tohoku $J$. exp. Med., 1970, 101, 299-309. 